\title{
2. EFFECT OF SUSPENDED SEDIMENT CONCENTRATION ON REMOTE SENSING REFLECTANCE AND LIGHT PENETATION DEPTH
}

\author{
Asif Mumtaz Bhatti ${ }^{1}$, Seigo Nasu ${ }^{2}$ and Masataka Takagi ${ }^{3}$
}

\begin{abstract}
The purpose of the research was to investigate the effect of suspended sediment concentration on remote sensing reflectance and depth of light penetration in the turbid water. Turbidity is not a uniform parameter, either spatially or temporally. Laboratory based experiments were performed to establish relationship between the hyperspectral remote sensing reflectance signal and suspended sediment concentration (SSC). The indoor spectral reflectance was measured $1 \mathrm{~m}$ above the water surface using both hyperspectral Field SpecPro FR Spectroradiometer and quantum sensor. The experiments were performed in the electromagnetic spectrum region of $400 \mathrm{~nm}$ to $900 \mathrm{~nm}$ keeping all environmental parameters constant. A relationship for PAR (Photosynthetically Active Radiation) transmittance, reflectance and absorption with varying levels of SSC was illustrated. The reflectance and diffuse attenuation coefficient increase with the increase in SSC. The first derivative of peak reflectance, at $827 \mathrm{~nm}$, correlated strongly with SSC than the peak reflectance itself. Model was developed to quantify the suspended sediment concentration.
\end{abstract}

Keywords: Remotely sensed data, Suspended sediment, First Derivative, NIR

\section{Introduction}

Water quality of reservoirs, rivers, coastal waters and estuaries undergoes significant changes owing to many influencing factors. Sustainable development demands a deeper knowledge of the interaction among economy, society and water resources. One important water quality issues is suspended sediments originating from soil erosion. Soil erosion is a widespread problem causing the deterioration of both land \& water resources. Sediments, which fill lakes, reservoirs, and dams, are one of the most important environmental problems throughout the world. High concentrations of suspended sediment in water are a critical element in the economic feasibility of a project and could shorten the useful life of many reservoirs \& dams. Monitoring of suspended sediments in water bodies is imperative for proper water resources and environmental management. Suspended sediment load carried by streams varies considerably both in quality and quantity as it comes from a variety of sources. The major portion of suspended sediments is caused by soil erosion. However, certain amount also originates from weathering of rocks from beds and banks of stream. Most of the sediment which is eroded from the land surface is in the form of fine particles which are transported in water courses as a suspended load.

The most often cited estimates of the global suspended sediment discharge to the ocean range between $15 \times 10^{9} \mathrm{t} \cdot \mathrm{yr}^{-1}$ to $20 \times 10^{9} \mathrm{t} \cdot \mathrm{yr}^{-1}$ where the best estimate may be about $20 \times \times 10^{9} \mathrm{t} \cdot \mathrm{yr}^{-1}$ [1], of which over $25 \%$ is considered to be trapped by dam reservoirs [2]. Identification of these sources and quantifying their effect is a major task for environmental technologist and water resources planners [3]. This necessitates a comprehensive study of suspended sediments, quantitative relation of sediment to the water flow, and the quantity of total sediment deposited in reservoirs. Remote sensing of water quality is appealing to the resource managers because it offers not only multi-temporal spatial data but also synoptic view that is not possible through exiting conventional, time consuming and expensive analytical data collecting systems. Several studies have been conducted to address the impact of suspended sediments on the spectral profile of surface waters. Most of these studies focus on the relationships between spectral reflectance and suspended sediment concentrations in surface waters. Few studies actually address how different sediment types and size affect spectral reflectance [4] [5] [6].

It is imperative to determine the quantity, distribution, type of suspended sediments, and optimal wavelength to enhance the reliability and applicability of remotely sensed data for water quality monitoring. Remote sensing makes it possible to monitor the water bodies effectively $\&$ efficiently and, identifying areas with significant water quality problems.

\footnotetext{
${ }^{1} \mathrm{PhD}$ Student, Department of Infrastructure Systems Engineering,, Kochi University of Technology, Tosayamada-cho, Kami-City, Kochi, 782-8502,Japan. asifmumtaz.bhatti@kochi-tech.ac.jp

${ }^{2,3}$ Professor, Department of Infrastructure Systems Engg., Kochi University of Technology, Kochi, Japàn.
} 
The incident energy on the water surface is reflected, absorbed, and/or transmitted. The transmitted, absorbed and scattered energy vary with quality and quantity of suspended sediments in water bodies. In remote sensing techniques the reflected energy is measured, carrying some information of the object from which it is reflected. Reflectance is function of many influencing factors that caused the change in reflectance signals. Different channels have their own properties and show different spectral characteristics. Rational feature selection is imperative for analysis and information extraction of hyperspectral data. Research on processing, analysis and information extraction of hyperspectral data should be strengthened to determine more useful information, make full use of the advantage and potential of hyperspectral remote sensing technology and promote the development of new and important technology [7].

While dealing with suspended sediments, the characteristics of the sediments including size, shape and texture of the particles must be taken into consideration. In order to investigate the effects of varying concentrations and composition of suspended sediments on the spectral signature of surface waters, series of controlled experiments were conducted. In the present research work the hyperspectral data of different suspended sediments, spectral characteristics, and correlation between first derivative and SSC is comprehensively analyzed.

\section{Experimental Methodology}

In this study four different types of soils were used to evaluate the effect of particle size, shape and texture variation on remote sensing reflectance. First type of soil, silty red soil was collected from the central area of Okinawa Island (coordinates: $26^{\circ} 23^{\prime} \mathrm{N}$ and $127^{\circ} 73^{\prime} \mathrm{E}$ ). While the second type kaolin was readily available from the market. The third type silty red soil $(50 \%)$ and kaolin $(50 \%)$ was prepared at the laboratory to elucidate the effect of colour and texture of soil on the spectral reflectance. Also, vary fine sand was used to study the effect of size and texture on reflectance spectra. All types of soil samples were air dried and manually sieved to ensure a uniform sediment size. The experiments were conducted indoor in a black painted room at Kochi University of Technology, Japan and Center for Advanced Land Management Information Technologies (CALMIT), University of Nebraska- Lincoln, USA. A hyperspectral Field SpecPro FR Spectroradiometer (Analytical Devices, Inc., Boulder, CO) was used to collect the upwelling radiance from the water surface.

The sieved soil samples were weighted to produce fifty concentrations of suspended sediments ranging from 20 to $1000 \mathrm{mg} / \mathrm{l}$. Initial reflectance readings were taken for the water tank prior to the addition of any suspended sediments and sediments were added systematically to the water-filled tank to enable spectra to be collected for a range of SSC. To study the SSC and reflectance relationship, the mean of ten scans was used for analysis.

The soil sediments were kept in suspension by manually stirring at regular intervals. The depth of water column was 60 am and was kept constant for all experiments The water tank was scanned within 15 seconds of addition of sediments in order to minimize settling of input sediments. The sensor of spectroradiometer was positioned perpendicular at the center of the tank to achieve nadir view. The distance of the sensor from the water surface was kept fixed at the height of 1 meter above the sample, yielding an instantaneous field of view (FOV) $1.75 \mathrm{~cm}$. For this study, data from 400 to $900 \mathrm{~nm}$ was used because noise was pronounced at wavelength shorter that $400 \mathrm{~nm}$ and longer than $900 \mathrm{~nm}$. To illuminate the tank uniformly, two 500 watt tungsten halogen lamps illuminated from 1 meter above water surface with a beam inclination of $30^{\circ}$. All sides of the tank were painted black to minimize potential bottom and side effects. Radiation input to the ASD FieldSpec FR spectrometers is through a fiber optic bundle, 5 meters in length. The fiber optic cable provides the ability to quickly and easily point the spectrometer field of view at different targets, especially when using the pistol grip. Measurements pertaining to the underwater irradiance at certain depth with varying sediment loads were made using four Li-192SA underwater quantum sensors.

Reflectance was calculated as a simple ratio between target and reference panel using following equation.

$$
R(\lambda)=\frac{L(\lambda)}{S(\lambda)} \times C a l \quad(\lambda)
$$

Where $L(\lambda)$ is the radiance measured from the water surface, $S(\lambda)$ is the radiance from the reference panel measured under the same illumination conditions and $\mathrm{Cal}(\lambda)$ is the calibration factor for the reference panel. The reference plaque was a Labsphere white Spectralon of dimensions $12.5 \mathrm{~cm} \times 12.5 \mathrm{~cm}$ which was specially designed and calibrated to reflect natural white light with minimum absorption. 


\section{Results and Discussion}

\subsection{Effect of SSC on Remote Sensing Reflectance}

Reflectance is the function of quantity and characteristics of suspended sediments. There is no standard algorithm for the estimation of suspended sediments due to the complex nature and composition of the suspended sediments. The spectral reflectance of water with different types of suspended sediments and concentration of $1000 \mathrm{mg} / 1$ is shown in figure 1 . The reflectance tends to increase with the increase in SSC, with a few minor exceptions. The wavelengths of peak reflectance were plotted against SSC (Figure 2). When SSC is low the peak reflectance occurred at short visible wavelengths, but when SSC is high the peak

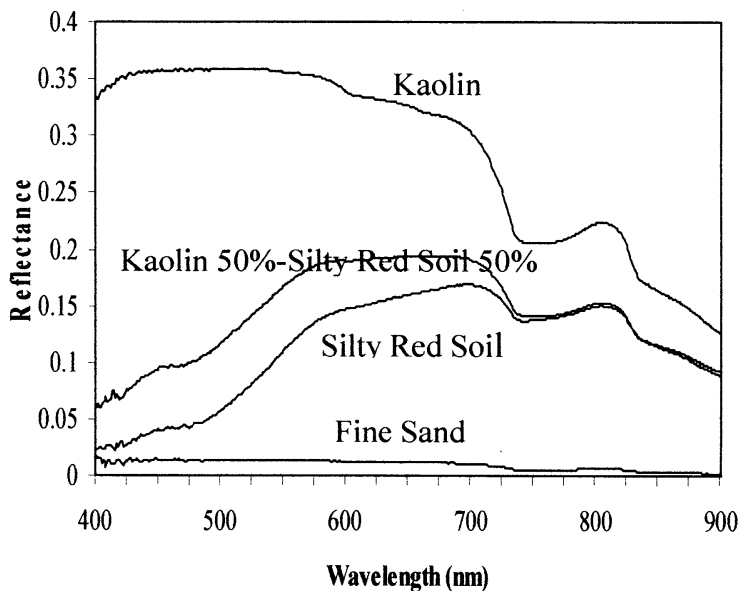

Figure 1: Spectral Reflectance of water with different types of soil

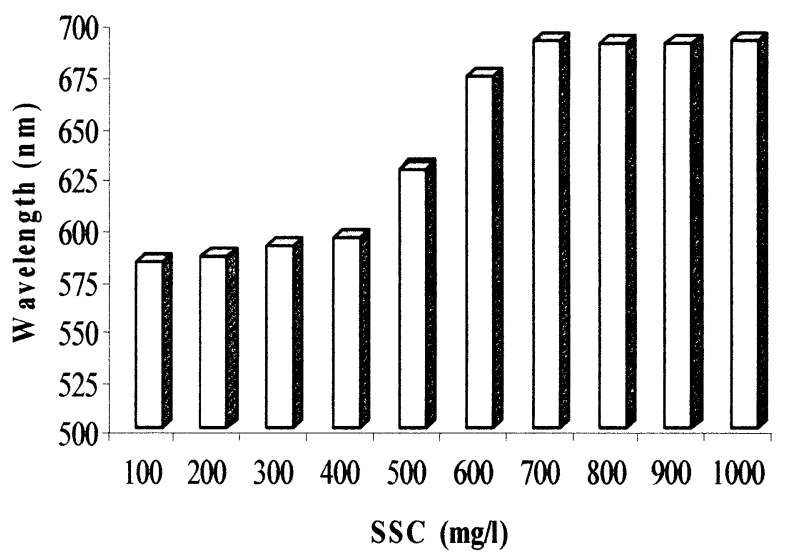

Figure 2: Wavelength of peak reflectance with varying SSC

reflectance shifted towards longer wavelength. Below $400 \mathrm{mg} / \mathrm{l}$, the reflectance occurred around $575 \mathrm{~nm}$ with only minor differences. Above $400 \mathrm{mg} / 1$ the peak reflectance shifted to $675 \mathrm{~nm}$ and increase slightly with increase in sediment load. Maximum reflectance was observed in the visible domain and high absorption is in the NIR. With the increase in the suspended sediments, spectral reflectance increase and peak reflectance shifts towards longer wavelengths. The spectral reflectance of silty red soil is plotted against $\mathrm{SSC}$ as depicted in figure 3. The qualitative nature of the spectral curves are similar in all cases, however, there is considerable variance in the magnitude of spectral reflectance. The low reflectance value is due to the black coated inner walls of the tank, which absorb much of the incident light. At levels of $600 \mathrm{mg} / \mathrm{l} \mathrm{SSC}$ and above, the spectral profile becomes somewhat irregular in all cases, suggesting that the relationship between reflectance and SSC was found to be nonlinear.
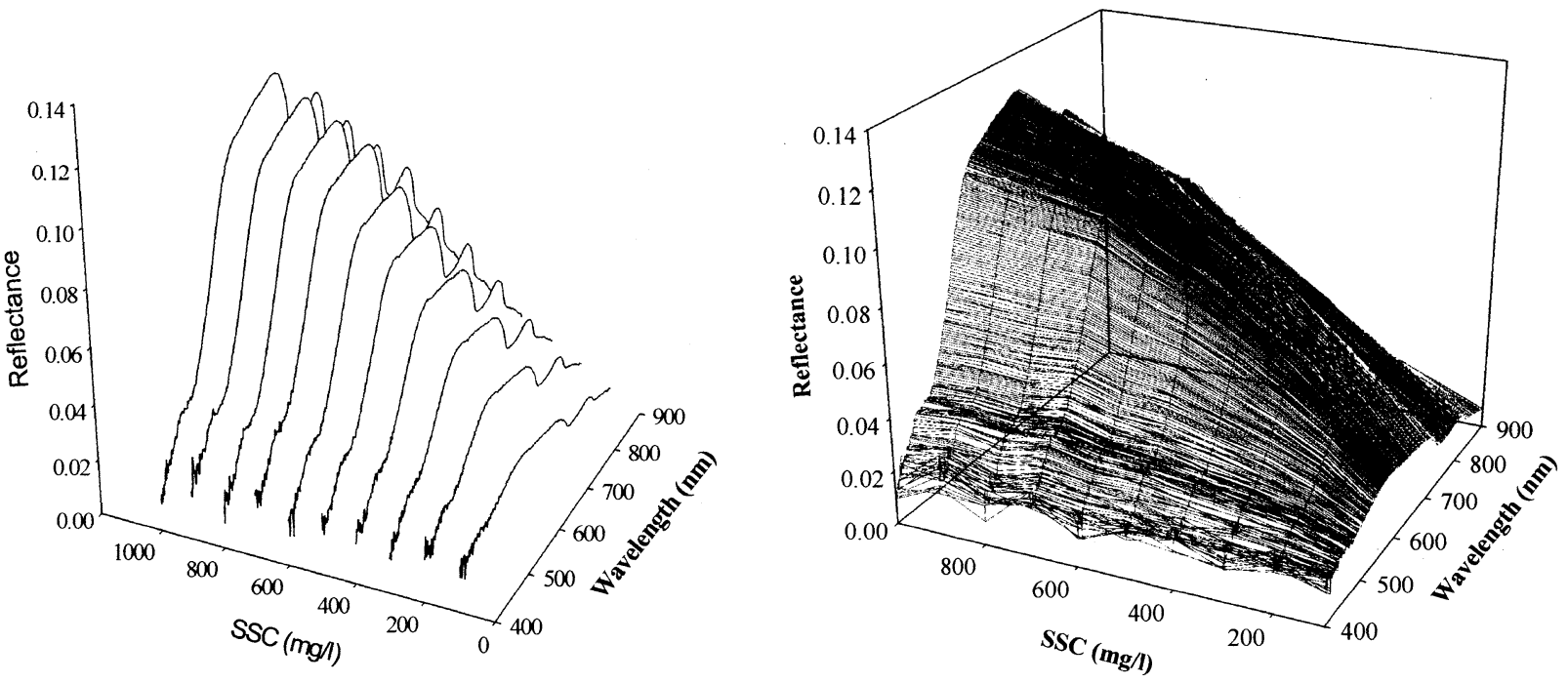

Figure 3: Spectral reflectance of water with varying concentration of silty red soil 
The first derivative of a spectral reflectance can be defined as the rate of change of reflectance with respect to wavelength $(\mathrm{dy} / \mathrm{dx})$. The spectral data were partitioned into narrow bands each having $5 \mathrm{~nm}$ width. The derivatives were computed by dividing the percentage reflectance difference between last and first percentage reflectance value of each narrow band by the wavelength interval separating them. The derivative spectra seem visually separable below SSC concentration of $500 \mathrm{mg} / 1$ with peak separation occurring at 827 $\mathrm{nm}$ (Figure 4). However, above $500 \mathrm{mg} / \mathrm{l}$, the curves seem visually identical.
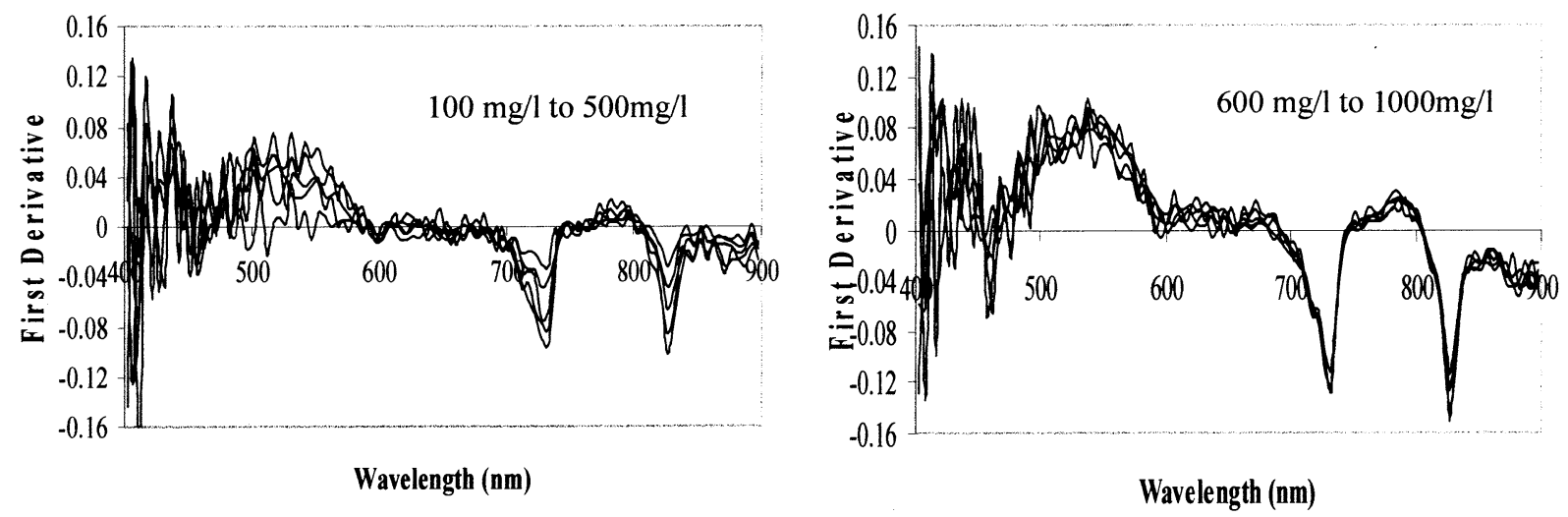

Figure 4: First derivative spectra with varying SSC

The derivatives tended to be positive in visible domain and shift towards negative in the NIR domain. The regression model was developed in order to examine the relationship between first derivative and SSC (Figure 5). The inverse second order equation of the following form can be used to estimate the SSC.

$$
\operatorname{SSC}(\mathbf{m g} / \mathbf{l})=\mathbf{a}+\mathbf{b} / \mathbf{x}+\mathbf{c} / \mathbf{x}^{2}
$$

Where $\mathrm{a}, \mathrm{b}$ and $\mathrm{c}$ are regression coefficients and $\mathrm{x}$ is the derivative reflectance of the selected wavelength.

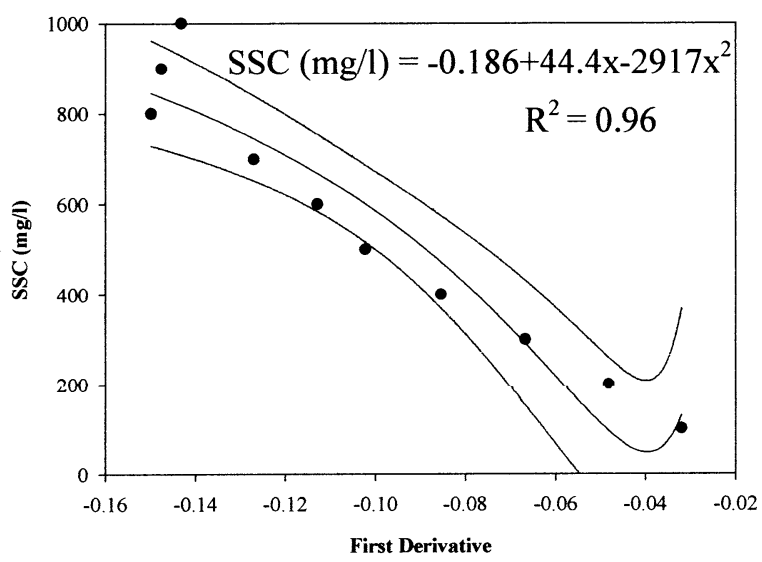

Figure 5: Correlation between SSC and first derivative at $827 \mathrm{~nm}$

\subsection{Effect of SSC on Depth of Light Penetration}

The quantum instrument record amounts of photosynthetically active radiation (PAR-400 to $700 \mathrm{~nm}$ ) in the water, measure photosynthetic photon flux density (PPFD) in micromoles per second per meter squared $\left(\mu \mathrm{mols} \mathrm{s}^{-1} \mathrm{~m}^{2}\right.$. The quantum sensors were placed first at the depth of $30 \mathrm{~cm}$ and then $60 \mathrm{~cm}$ from the water surface, with one facing upward to measure the downwelling irradiance $\left(E_{\mathrm{do}}\right)$ beneath the surface and the other facing downward to measure the upwelling irradiance $\left(E_{u}\right)$. The optical properties of water are functions of underwater irradiance, such as the vertical attenuation coefficient for downward irradiance or irradiance reflectance.

The measurements $E_{d o}$, underwater downwelling irradiance at depth $\left(E_{d}\right)$, upwelling irradiance from the tank bottom and water column $\left(E_{u}\right)$ and PAR reflectance form the water surface $R$, in conjunction with variable SSC, allowed us to examine the energy budget for PAR in the water. The effect of depth and SSC 
on upwelling irradiance (figure 6) was also examined. $E_{\mathrm{u}}$ is a complex parameter because it should be dependent on the total radiation incident to the surface, SSC in the water column and any reflective effect of the bottom itself [8]. When electromagnetic energy reaches the surface water body, it may be reflected, absorbed, or transmitted. The interrelationship among these three processes can be expressed as

$$
\mathbf{E i}=\mathbf{E a}+\mathbf{E} \mathbf{t}+\mathbf{E r}
$$

Where $\mathrm{Ei}$ is the incident energy; Ea is absorbed energy (100-Et-Er); Et is transmitted energy $\left(\mathrm{E}_{\mathrm{d}} / \mathrm{E}_{\mathrm{do}}\right)$; and $\mathrm{Er}$ is reflected energy $\left(R-E_{u} / E_{d o}\right)$. The interrelationship involving PAR transmittance, reflectance, and absorption (in percent) with varying SSC is shown in figure 7. Both the downwelling and upwelling irradiance below the water surface decreased with increasing SSC.

$$
\text { SSC (mg/l) }
$$

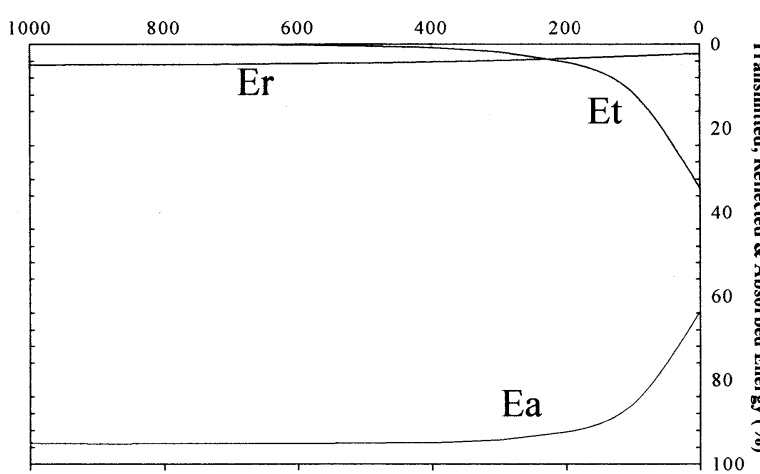

Figure 6: PAR Budget with varying SSC

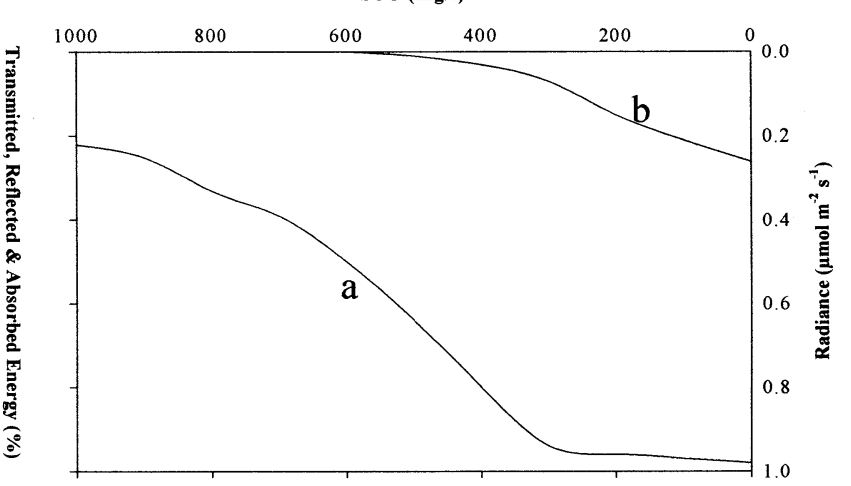

Figure 7: Upwelling irradiance (Eu) at $30 \mathrm{~cm}$ (Curve a) \& $60 \mathrm{~cm}$ (Curve b) depth from water surface with varying SSC

The diffuse attenuation coefficient $(\mathrm{k})$ is derived from the Beer-Bouger Law and can be calculated using the following equation.

$$
k=\left[\ln \left(E_{d o}-E_{d}\right)\right] / d
$$

Where $E_{d o}$ is the irradiance at the surface, $E_{d}$ is the irradiance at depth and $d$ is the distance between the sensor at depth and the sensor at the surface.

The diffuse attenuation coefficient $\mathrm{k}$ quantifies the "quenching" of light as it passes from the water surface to the quantum sensor at the depth of $60 \mathrm{~cm}$. The relationship between SSC and $\mathrm{k}$ is important because the level of turbidity of a water body can be measured by means of computing $\mathrm{k}$, instead of measuring SSC. The results of relationship between SSC and k are summarized graphically as figure 8 . Suspended sediment concentrations can be estimated by extension coefficients using a linear regression model of the form

$$
k=9 E-05(S S C)+0.021
$$

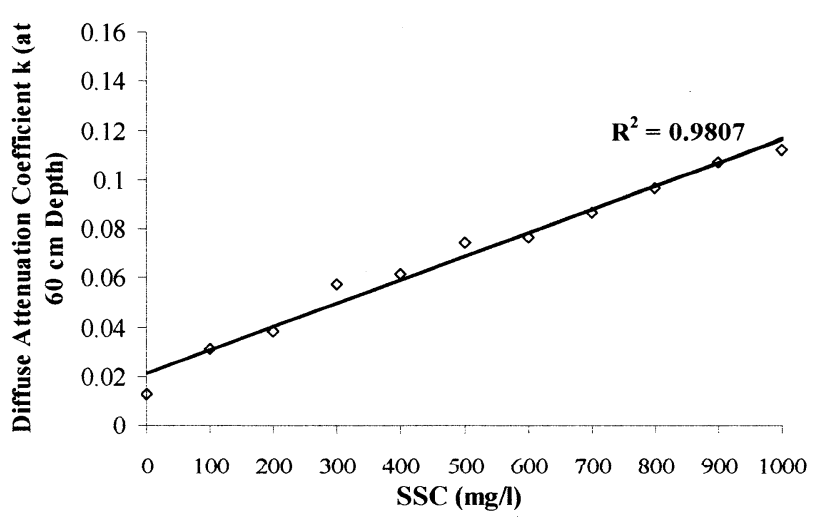

Figure 8: Relationship between SSC and extinction coefficient 


\section{Conclusions}

Based on the laboratory conducted study, the following inferences are drawn: 1) The reflectance increased with the increase in SSC for all types of soil. Between 700 to $900 \mathrm{~nm}$ (NIR) the reflectance increases more uniformly with increase in SSC; 2) The soil type, particle shape and texture played a dominant role in affecting the spectral reflectance. The shape and magnitude of the spectra reflected from water is strongly influenced by type and amount of suspended sediments; 3 ) In the visible domain, with increase in SSC, there is small increase in reflected energy compared to a large increase in energy absorbed; 4). The first derivative proved to be effective in estimating SSC; 5) The diffuse attenuation increase with the increase in SSC and the relationship is linear; and 6) At a depth of $60 \mathrm{~cm}$, in the visible domain, there was no bottom effect when suspended sediment concentrations were above $400 \mathrm{mg} /$ liter.

To develop more generalize model for predicting suspended sediment concentration, effect of suspended sediments distribution with depth and application of remotely sensed data with different environmental condition needs evaluation. It is further concluded that sustainable water resources management in an organized and coordinated way will be key measures for sustainable development.

\section{Acknowledgments}

The research work was financially supported by the Kochi University of Technology, Kochi Japan. The assistance of all members of Nasu Lab is gratefully acknowledged.

\section{Reference:}

[1]. Walling, D. E. and Webb, B. W. (1996), "Erosion and Sediment Yield: global overview, Proceedings of the Exeter Symposium, July 1996, IAHS Publication No. 236, 3-19.

[2]. Vorosmarty, C. J., Meybeck, M., Fekete, B. and Sharma, K. (1997), "The potential impact of neo-Cartorization on sediment transport by the global network of rivers", In: Proceedings of the Rabat Symposium, IAHS Publication No. 245,261-273.

[3]. D.S. Bhargava and D.W. Mariam (1991), "Light penetration depth, turbidity and reflectance related relationships and models", Journal of Photogrammetry \& Remote Sensing, 46 (1991) 217-230.

[4]. Lodhi et al. (1997), "The potential for remote sensing of loess soils suspended in surface waters", Journal of the American Water Resources Association, 33, 111-117

[5]. Bhargava, D. S., and Mariam, D. W. (1990), "Spectral reflectance relationships to turbidity generated by different clay materials", Photogrammetric Engineering and Remote Sensing, 56, 225-229.

[6]. Bhargava, D. S., and Mariam, D. W. (1991), "Effects of suspended particle size and concentration on reflectance measurement", Photogrammetric Engineering and Remote Sensing, $57,519-529$.

[7]. Mazar, A. S., Martin, M., Lee, M., and Dolomon, J. E. (1988), "Image processing software for imaging spectrometry data analysis", Remote Sensing of Environment, 24, 201-211.

[8]. L. Han \& D. C. Rundquist (1994), "The response of both surface reflectance and the underwater light filed to various levels of suspended sediments: preliminary results", Photogrammetric Engineering \& Remote Sensing, Vol. 60, No. 12, 1463-1471. 